\title{
O Feminismo Árabe-Muçulmano à Luz da Teoria Feminista das Relações Internacionais
}

\author{
Arab-Muslim Feminism in Light of Feminist Theory of International Relations
}

DOI: https://doi.org/10.22456/2178-8839.113864

Sophia Teixeira e Souza

Universidade Federal do ABC (UFABC), São Bernardo do Campo, Brasil

sophiatesouza@gmail.com (

Julia Bertino Moreira

Universidade Federal do ABC (UFABC), São Bernardo do Campo, Brasil

julia.bertino@ufabc.edu.br

\section{Resumo}

A Teoria Feminista das RI, por ser produzida no Norte Global, não proporciona o arcabouço epistemológico adequado para a inve stigação sobre mulheres árabes e muçulmanas. Destarte, o artigo tem como problema de pesquisa identificar: como as feministas árabes e muçulmanas contribuem para fazer avançar o debate teórico feminista do Sul Global nas RI? A hipótese é de que o diálogo é sustentado pelo compartilhamento de obstáculos semelhantes convivência com conservadorismos religiosos, participação na vida pública nacional, entre outros - e pela identificação mútua de não-pertencimento ao feminismo hegemônico, praticado pelas instituições internacionais. Nosso objetivo, portanto, consiste em fazer uma revisão crítica da literatura teórica indispensável às novas pesquisas na academia brasileira. Começamos por uma breve revisão do feminismo pós-colonial (a partir do qual se constroem muitos argumentos feministas do Mundo Árabe); passamos pelas particularidades da interseccionalidade nos estudos de mulheres árabes; apresentamos suas principais teóricas e, por fim, identificamos que sua contribuição para o avanço do debate feminista nas RI do Sul Global consiste, em suma, no seu combate aos reflexos de processos imperialistas passados e recentes, que reproduzem estruturas sociais de manutenção da subalternidade das mulheres.

Palavras-chave: Teoria das Relações Internacionais; Feminismo; Mundo Muçulmano;

\begin{abstract}
The Feminist Theory of IR, having been produced in the Global North, does not provide the adequate epistemological framework for research on Arab and Muslim women. Thus, the article has the research problem to identify: how Arab and Muslim feminists contribute to advancing the feminist theoretical debate of the Global South in IR? The hypothesis is that the dialogue is supported by the sharing of similar obstacles - living with religious conservatism, participation in national public life, among others - and by the mutual identification of non-belonging to the hegemonic feminism, practiced by international institutions. Our objective, therefore, is to carry out a critical review of the theoretical liter ature indispensable for new research in the Brazilian academy. We begin with a brief review of post-colonial feminism (from which many feminist arguments in the Arab world are constructed); we go through the peculiarities of intersectionality in the studies of Arab women; we present their main theore ticians and, finally, we identify that their contribution to the advancement of the feminist debate in the IRs of the Global South consists, in short, in its fight against the reflexes of past and recent imperialist processes, which reproduce social structures that maintain the subordination of women.
\end{abstract}

Keywords: International Relations Theory; Feminism; Muslim world; 


\section{Introdução}

Os estudos feministas sobre mulheres árabes, quando especificamente circunscritos nas Relações Internacionais (RI), impõem desafios particulares às pesquisadoras brasileiras, alguns mais visíveis do que outros. A questão da diferença cultural entre pesquis adora e sujeitas de pesquisa não passa desapercebida, o que torna a ética parte fundamental da teorização (ACKERLY, 2008; SYLVESTER, 2004), por ser muito comum que estudemos mulheres em países longínquos. Esses temas apresentam as limitações da Teoria Feminista das RI que, tendo já consagrado autoras como Tickner, Sylvester e Enloe, ainda concentram sua produção acadêmica no Norte Global.

Presentes nos estudos de muitas populações femininas nas RI, sobretudo porque foram as primeiras a denunciar o caráter masculino e sexista dos conceitos centrais e das consequências do estadocentrimo (ENLOE, 2014; SYLVESTER, 2004, 2008; TICKNER, 1997, 2014) na disciplina, as teóricas feministas das RI ${ }^{1}$ contribuíram largamente para os estudos de gênero no nosso campo à medida em que desconstruíram categorias enrijecidas pelos anos de vigência e apontaram a problemática da suposta neutralidade ao não se falar das mulheres.

Quando pensamos em populações femininas em sociedades do Sul Global, no entanto, essas perspectivas consolidadas não são suficientes, uma vez que perpetram - ainda que visando uma sororidade global - a imagem das mulheres doSul comovítimas e das mulheres do Norte, como salvadoras. Esses elementos reforçam, ainda, as perspectivas securitizadas nos estudos do Sul Global, pois presume-se que conflitos armados são o único aspecto interessante ao estudo dessas localidades. Propomos, portanto, trazer autoras e perspectivas teóricas pouco conhecidas no Brasil, mas que muito podem acrescentar às pesquisas feministas sobre o Sul produzidas pelo Sul.

Estas autoras e suas perspectivas não são diretamente oriundas de análises das relações internacionais e, portanto, encontram resistência das estudiosas e estudiosos de RI, por precisarem “emprestar” conceitos de áreas conexas. Destarte, nosso problema de pesquisa consiste em explorar os desafios da epistemologia feminista em RI nos estudos sobre mulheres árabes, guiando-nos pela seguinte pergunta: como as feministas árabes e muçulmanas contribuem para fazer avançar o debate teórico feminista doSul Global nas RI? Tal pergunta se contextualiza nos estudos pós -coloniais sobre as populações femininas do Mundo Árabe e deriva dos questionamentos acadêmicos céticos quanto à possibilidade da consolidação do feminismo enquanto teoria e práxis das RI e das relações internacionais; bem como do ceticismo em relação ao estudo de uma área geográfica tão dominada pelas análises securitárias.

A hipótese é de que o diálogo é sustentado pelo compartilhamento de obstáculos semelhantes - convivência com conservadorismos religiosos, participação na vida pública nacional, entre outros -e pela identificação mútua de nãopertencimento ao feminismo hegemônico, praticado pelas instituições internacionais. Como demonstraremos, as vertentes feministas, em sua diversidade, se valem de ferramentas analíticas e conceitos não independentes das RI ainda que sejam utilizados em sua raiz e predominantemente em análises a nível nacional ou micro.

De forma a demonstrar a expansibilidade da epistemologia feminista nas Relações Internacionais para além daquela proposta pelasfeministas do Norte Global, temos como objetivo geral empreender uma revisão crítica da literatura teórica que consideramos fundamental para os estudos das populações femininas árabes. P artindo de uma lógica de encadeamento das perspectivas, começamos a exposição pela teoria pós-colonial, e perpassamos a discussão sobre interseccionalidade, culminando na apresentação dos debates internos ao feminismo árabe -muçulmano.

O método da revisãobibliográfica é de utilidade por se tratar de uma parte fundamental da pesquisa feminista: a de observar e refletir sobre conceitos e teorias aos quais recorremos cotidianamente, para que possamos ponderar e avaliar a aplicabilidade de opções às nossas pesquisas ${ }^{2}$. Isto é, a revisão crítica da literatura nos permite estabelecer diálogos entre textos consolidados no campo e aqueles mais recentes; entre autoras já célebres e autoras menos

\footnotetext{
1 Autoras consolidadas na academia brasileira, que derivaram diretamente de críticas às teorias tradicionais das RI e do olhar crítico de gênero para com as demais teorias pós-positivistas das RI.

2 "Feminists review the literature and consider the merits of various options relative to our research question" (ACKERLY; TRUE, 2006, p. 33).
} 
conhecidas, porém não menos merecedoras de leitura; pensar nos contextos e objetivos para os quais cada conceito e abordagem foram formulados, verificando se continuam relevantes ou se devem ser complementados, reformatados ou mesmo descartados.É importantelembrar que a pesquisa feminista, apesar de solitária, depende de uma rede de mulheres produzindo conhecimento - as que nos antecederam, as nossas contemporâneas e as de mesma geração -; é coerente, portanto, que retomemos as reflexões disponíveis, sobretudo porque os problemas a serem superados pelos feminismos não deixaram de existir.

A primeira parte do texto fará um sobrevoo sobre as teorias pós-coloniais; isso é relevante, pois é fundamental descolonizar o olhar da pesquisadora e da mulher do Mundo Árabe. A segunda parte trará uma introdução à ferramenta da interseccionalidade nos estudos de gênero e da sociedade civil como um todo; tal ferramenta aproxima os estudos sob a Teoria Feminista das RI dos estudos pós-coloniais sobre as desigualdades no contexto mundial. A terceira parte tratará especificamente das perspectivas de teóricas do feminismo árabe-muçulmano e evidenciará a imprescindibilidade da interseccionalidade para a abordagem. Finalmente, encaminha-se para as considerações finais, retomando-se os pontos de argumentação aolongo do texto que sustentam a hipótese.

\section{Teorias pós-coloniais e interseccionalidade}

A corrente dos estudos feministas pós-coloniais é representada por autoras oriundas de países do Sul Global ${ }^{3}$. Tendo como expoentes autoras doSul Asiático (Spivak, Mohanty, Mahmood) e do MundoÁrabe (Abu-Lughod), a proposta do feminismo dentro dos movimentos intelectuais pós -coloniais é de analisar como a (re)produção da diferença gênero, classe e raça dentro da sociedade nacional é manipulada pelo etnocentrismo colonizador de modo a manter a sociedade colonizada na periferia do sistema internacional.

Grande referência da teoria feminista pós-colonial, a indiana Gayatri Spivak aborda ofeminismo contemporâneo, sua relação com os movimentos pós-coloniais e as teorias do multiculturalismo e da globalização. É fundamental sua crítica à representação do sujeito do Terceiro Mundo no discurso ocidental, o qual considera colaborativo com os interesses econômicos e neocoloniais do Ocidente (SPIVAK, 2010). A crítica a uma produção intelectual que ela não chama de orientalista, mas que busca colonizar de novoe/ou manter a subalternidade do sujeito terceiro-mundista, é feita no sentido de evidenciar o imbricamento entre a mulher intelectual - a feminista branca - e a mulher subalterna. Esta é a grande contribuição que Spivak faz ao debate: a identificação da subalternidade ${ }^{4}$ nos indivíduos do Terceiro Mundo em relação aos do Primeiro.

A preocupação de Spivak é de lembrar ao intelectual pós -colonial, seus pares, que não pode falar pelo seu objeto de estudo, o indivíduo subalterno, sem que seja cúmplice do mesmo sistema que critica pois presume, mais uma vez, que o subalterno não pode falar por si só. Constitui-se, então, o subalterno como objeto de conhecimento científico, e não como sujeito (SPIVAK, 2010). Esta arguição funciona como uma crítica, aqui, às feministas anglo-saxônicas, francesas e, inclusive, às teóricas feministas das RI que mencionamos anteriormente. Isto é, ao focarem seus estudos na vitimização das mulheres na guerra ou na sua participação em operações de paz e afins, essas feministas assumem para si o papel de porta-voz das mulheres subalternas, mantendo-as como tal e, portanto, como objetos de estudo.

Isto posto, Ackerly (2008) defende que a primeira pergunta que uma pesquisadora feminista deve se colocar, seja lendo um texto, analisando dados e até produzindo seu próprio trabalho, é a quais interesses as perguntas de pesquisa servem, uma vez que as escolhas da pesquisa significam exercícios de poder em si mesmas. Ackerly defende que um

\footnotetext{
${ }^{3}$ Seguimos o entendimento sobre o Sul Global a partir das seguintes autoras: "[...] the South has been constituted through a long history of unequal encounters with, and diverse forms of resistance to, different structures and entities across what can bevariously designated the North, West or specific imperial and colonial powers" (DALEY; FIDDIAN-QASMIYEH, 2020, p.3).

4 Subalternidade, em Spivak (2010), corresponde ao indivíduo do Sul Global (aqui, mulher) ao qual a fala direta não é permitida. Esta é intermediada e representada pelos intelectuais ocidentais que, ao falarem por eles, lhes negam a própria subjetividade. Os intelectuais ocid entais, assim, empurram o sujeito colonizado mais ainda para a posição de subalterno porque não os supõem capazes de falar por si. Dessa forma, "A prod ução intelectual ocidental é, de muitas maneiras, cúmplice dos interesses econômicos internacionais do Ocidente” (SPIVAK, 2010, p. 20).
} 
trabalho é feminista quando levamos em consideração como as descobertas podem ser usadas e como afetarão nossos sujeitos de pesquisa, uma vez que ofazer do feminismo na academia tem responsabilidades éticas:

A teoria feminista educa empiristas feministas sobre a importância ética da reflexão epistemológica a cada passo da pesquisa. E a teoria feminista informa as escolhas metodológicas de qualquer pesquisadora feminista. Finalmente, a maior parte das pesquisas feministas é conscientemente deliberada em seu propósito pedagógica. As escolhas que feministas fazem sobre onde e como compartilhar e ensinar são, elas mesmas, metodológicas (ACKERLY, 2008, p. 30, tradução nossa) 5 .

Assim, essa autora mostra como resolver esse paradoxo da metodologia feminista - ouvir e estudar as experiências das sujeitas subalternas sem reproduzir um papel de colonização do discurso - aplicada às RI.

Os argumentos de Spivak, ainda, concentram-se na defesa do dever acadêmico ${ }^{6}$ de revelar os discursos, as identidades e diversidades escondidas pela alteridade artificialmente constituída das populações colonizadas e que não as reconhece como sujeitos, mas como objetos de estudos e de ação política internacional. Isto é, objetos de violência epistêmica, de apagamento da identidade e da subjetividade: “[...] o desenvolvimento do subalterno é complicado pelo projeto imperialista” (SPIVAK, 2010, p. 55). A autora explica que: “[...] o imperialismo estabelece a universalidade da narrativa do modo de produção, e que ignorar o subalterno hoje é - quer queira, quer não - continuar o projeto imperialista" (SPIVAK, 2010, p. 97). Desse modo, Spivak faz um chamamento à própria comunida de científica do Terceiro Mundo e Ackerly adapta essa demanda ética para as RI, de forma a não circunscrever a academia feminista ocidental apenas a temas de estudo geograficamente-e mesmo culturalmente-próximos.

Como mulher de pele escura, Spivak reconhece que a situação da mulher subalterna do Sul é de dupla obscuridade, isto é, duplamente mais longe da possibilidade de fala do que de uma acadêmica não branca e, consequentemente, da possibilidade de se fazer ouvir. Segundo sua lógica, é possível dizer que o feminismo branco promove "[...] inclusão positivista de uma coletividade monolítica de "mulheres" na lista dos oprimidos cuja subjetividade inquebrantável lhes permita falar por si mesmas contra um 'mesmo sistema' igualmente monolítico” (SPIVAK, 2010, p. 40). A solução para tal impasse é que a mulher intelectual utilize seu poder discursivo e acadêmico para criar espaços e oportunidades onde a própria subalterna poderáfalar por si e, tão importante quanto, encontre disposição para ser ouvida.

Igualmente indispensável quando se pretendem abordagens feministas pós -coloniais, o pensamento da indiana Chandra Mohanty converge frequentemente com o de Spivak, sendo seu marcante diferencial a crítica direta às feministas ocidentais e a relação mais explícita com o feminismo negro, através da ferramenta da interseccionalidade. Especificamente, o problema trabalhado por Mohanty é a fabricação da categoria "mulher do Terceiro Mundo" 7 pelas feministas ocidentais, de maneira a reafirmar hierarquias coloniais a partir da homogeneização. Esse fenômeno acontece porque os feminismos ocidentais tomam para si a autoridade de falar sobre as vidas das mulheres de diferentes classes, religiões e etnias do Terceiro Mundo de modo a homogeneizar suas experiências, novamente representando-as como vítimas desprovidas de ação (MOHANTY,1984).

Sem a intenção de fazê-lo, feministas ocidentais acabam por exercer um poder discursivo que afirma as condições de vida das mulheres ocidentais melhores do que as das mulheres em sociedades pós-coloniais. Destarte, ignoram as diferenças essenciais entre as economias centrais e periféricas e as consequências das políticas econômicas dependentes da ação do capital externo no bem-estar das populações de mulheres nesses países. Mohanty $(1984$, p. 336) chama a

\footnotetext{
5 "Feminist theory educates feminist empiricists about the ethical importance of epistemological reflection at every stage of the research process. And feminist theory informs the methodological choices of any feminist researcher. Finally, most feminist research is self-consciously deliberate in its pedagogical purpose. The choices that feminists make about where and how to share and teach our scholarship are themselves methodological" (ACKERLY, 2008, p. 30).

6 "A mulher intelectual como uma intelectual tem uma tarefa circunscrita que ela não deve rejeitar com um floreio" (SPIVAK, 2010, p. 126) .

7 Categoria não especificamente utilizada por Spivak, mas que engloba a figura da subalternidade, apesar de suas respectivas obras seminais serem contemporâneas.
} 
atenção das feministas e acadêmicas ocidentais para "a necessidade de examinar as implicações políticas de estratégias e princípios analíticos”.

Ademais, evidencia porque a interseccionalidadeinaugurada pelo feminismonegroé também fundamental para o pós-colonial. Isso é notável uma vez que a autorrepresentação feminista ocidental estabelece uma dicotomia em que sua ocidentalidade é privilegiada como referência e objetivo último da emancipação feminista. Desse modo: (1) define a sujeita "mulher" do Terceiro Mundo como submissa à opressão e incapaz de reagir; (2) desconsidera a resistência a nível pessoal e coletivo/civil, direcionando seu exame às instituições e sistemas (MOHANTY, 1984). Um feminismo transnacional pretendido pelas feministas ocidentais tal qual este, pensamos, aborda a transnacionalidade ao insistir em semelhanças de opressões universais: “O que une as mulheres é uma noção sociológica de ‘semelhança' das suas opressões” (MOHANTY, 1984, p. 337, tradução nossa). ${ }^{8}$ Essa “semelhança” é desconstruída pelas abordagens interseccionais e pelos feminismos árabes-muçulmanos. Pois, como afirma Mohanty (1984, p. 337, traduçãonossa):

A suposição das mulheres como um grupo já constituído e coerente, com interesses e desejos idênticos, independentemente de lugares e contradições de classe, etnia ou raça, implica uma noção de gênero ou diferença sexual ou até mesmo patriarcado (...) a qual pode ser aplicada universalmente e através das culturas. ${ }^{9}$

Essa presunção é o que produz a imagem de uma "mulher do Terceiro Mundo mediana" (MOHANTY, 1984). ${ }^{10}$ Trabalhamos, pois, com o conceito de interseccionalidade ${ }^{11}$ conforme definido por Bilge e Hill Collins: uma ferramenta analítica necessária para avultar a complexidade das desigualdades e arranjos de poder, sendo que as sociedades são formatadas por vários eixos de divisão social, os quais interagem e se influenciam entre si (BILGE; HILL COLLINS, 2016). Os eixos mais comumente trabalhados academicamente são os de gênero, classe e raça; aqui, dado o contexto de nossas sujeitas de pesquisas, os eixos de interseccionalidade estudados são gênero, religião, etnia e nacionalidade (BILGE; HILL COLLINS, 2016; MOHANTY, 1984). Eles não operam como aspectos mutuamente exclusivos ou hierárquicos, mas se constroem e se exercem um sobre o outro (BILGE; HILL COLLINS, 2016; MOHANTY, 1984).

Bilge trabalha a interseccionalidade relacionada ao conceito de agência e à alteridade produzida pelas feministas ocidentais ao se depararem com os modos de resistência das mulheres do Terceiro Mundo. Sua preocupação é com a percepção que feministas ocidentais têm das mulheres muçulmanas que vestem algum tipo de véu para expressar sua religiosidade. O véu é importante por ser um lugar de tensão entre diferentes correntes feministas e necessariamente interseccional, por imbricar os eixos da nacionalidade e da religião (BILGE, 2010). Tal tensão decorre da consideração feminista generalizada de que as práticas socioculturais da religião e, dado o período histórico, espe cificamente o islamismo, são proporcionalmente anuladoras da modernidade e do secularismo:

Paradoxalmente representadas tanto como vítima (passiva) da sua cultura/religião patriarcal opressiva e dos seus familiares homens, quanto como ameaça (ativa) à modernidade ocidental e cultura de liberdades, a mulher muçulmana de véu foi transformada em uma alegoria da diferença cultural indesejável (BILGE, 2010, p.10, tradução nossa). ${ }^{12}$

8 "What binds women together is a sociological notion of the 'sameness' of their opression" (MOHANTY, 1984, 337).

9 "The assumption of women as an already constituted, coherent group with identical interests and desires, r egardless of class, ethnic or racial location or contradictions, implies a notion of gender or sexual difference or even patriarchy (...) which can be applied universally and cross-culturally" (MOHANTY, 1984, p. 337).

10 "average third world woman" (MOHANTY, 1984, p. 337).

11 O termo é cunhado pela feminista negra Kimberlé Crenshaw a partir da década de 1980 e difundiu -se amplamente entre as feministas negras. No contexto das pesquisas sobre feminismo árabe-muçulmano, contudo, os marcadores identitários de etnia, nacionalidade e religião (não trabalhados pelo feminismo negro norte-americano) são pouco explorados. Optamos, pois, a apresentar a interseccionalidade conforme explorada por feministas não-brancas do Sul Global.

12 "Paradoxically portrayed both as a victim (passive) o her oppressive patriarchal culture/religion and male kin, and as a thre at (active) to Western modernity and culture of freedoms, the veiled Muslim woman has been turned into an allegory for undesirable cultural difference" (BILGE, 2010, p. 10). 
O caminho proposto por Bilge (2010) é, então, o de encontrar uma concepção de agência para a cidadania que contemple ouso do véu sem necessariamente deslocá-lo para um de dois polos predominantes na literatura: o véu como símbolo da submissão feminina aos padrões patriarcais da sociedade, segundo o feminismoliberal; e o véu como um símbolo de resistência à ocidentalização e à comodificação dos corpos femininos no combate à islamofobia, segundo o feminismo pós-colonial. Dessa forma, a performance social das mulheres poderia se libert ar de ser instrumentalizada por ambas as vertentes que, pretendendo falar em nome das mulheres que usam véu, não consideram as razões individuais para o usodela.

Bilge ainda indica, através da leitura de Abu-Lughod, que o afã de inspirar o ativismo e formas de resistência ao neoimperialismo-mesmode outros feminismos-do feminismo pós-colonial acaba romantizando os aspectos culturais que marcam a vivência das mulheres árabes e muçulmanas, empobrecendo as análises de poder. Por isso, ela atesta a validade da interseccionalidade para analisar a agência pois permite considerar articulações de poder e de subjetividade em diferentes contextos sociais, sem prescindir da relação de anterioridade entre a agência e o contexto. Admite -se,então, que contextos e formações sociais específicas geram diferentes formas de expressão da subjetividade e de agência e, mais uma vez, isso justifica a inadequação do feminismoliberal aos contextos do Mundo Árabe.

A socióloga israelense Nira Yuval-Davis, por sua vez, argumenta que interseccionalidade não corresponde à identidade e que, em concordância com as demais autoras, é uma ferramenta analítica muito relevante "que desafia abordagens hegemônicas dos estudos de estratificação e das formas reificadas de políticas identitárias” (YUVAL-DAVIS, 2006, p. 201, tradução nossa). ${ }^{13}$ Tal relevância contrapõe discursos de naturalização das diferenças que geram as desigualdades sociais; discursos estes que tendem a homogeneizar categorias sociais e lhes conferir atributos supostamente naturais e imutáveis, que delimitam a possibilidade de ação e são excludentes para uns e inclusivos para outros. São esses limites de ação que promovem a diferenciação e que reproduzem hierarquias de acesso a recursos econômicos, políticos e culturais em cada contexto. A autora sustenta que algumas divisões sociais, quais sejam os eixos, serão relevantes em algumas localidades e contextos históricos, mas não em outros (YUVAL -DAVIS, 2006). Nofeminismo árabe, a marcaçãoidentitária árabe ${ }^{14} \mathrm{e}$ o contexto político do Mundo Árabe não explicitam a cisão entre o que é árabe e o que é islâmico, uma vez que a religião muçulmana é oficial ou majoritária nos países da região. Dessa forma, assim comoo feminismo latino-americano é perpassado pela convivência com os reflexos sociais e institucionais do catolicismo, o feminismoárabe é perpassado pela convivência com estes reflexos, porém referentes ao Islã.

A ferramenta, portanto, é usada conforme as dimensões que a autora quer privilegiar em sua análise: as feministas árabes retomam a interseccionalidade como formulada pelas feministas negras em contraposição ao feminismo branco liberal. Ademais, a interseccionalidade no feminismo pós -colonial deve incorporar o eixo da nacionalidade, a qual confere possibilidades específicas dadas as configurações geopolíticas pertinentes. Isto fica claro ao diferenciar o olhar que o feminismo árabe tem para com as sociedades árabes: foco no gênero, nos direitos cidadãos e exercício da sexualidade heteronormativa. Enquanto que, ao olhar para as sociedades ocidentais, evidencia os eixos da islamofobia e da representação midiática enviesada das mulheres árabes.

Por esses motivos, a interseccionalidade é fundamental ao se pensar o feminismo árabe-muçulmano, em que os eixos que se intercruzam são: gênero, nacionalidade/origem/localização, religião ou etnia. Em suma, não se presume neutralidade, mas sensibilidade de não dispensar ou sobrepor uma categoria de análise sobre a outra, de modo a corresponder com o recorte de pesquisa pretendido pela pesquisadora. Como veremos a seguir, essa discussão é fundamental para compreendermos como se constitui e como se dá a contribuição do feminismoárabe -muçulmano.

13 "that challenges hegemonic approaches to the study of stratification as well as reified forms of identity politics" (YUVAL-DAVIS, 2006, p. 201).

14 "[...] it can be inferred that Arab nationalism has provided the historical conditions for the discursive practices related to Arab regionalism to articulate the distinct elements of the Arab identity (political, social, cultural and religious) into the unity (in diversity, it must be added) represented by the Arab region. In this sense, it is plausible to suggest that Arab regionalism, as the process by which the Arab region is made possible and that, at the same time, constitutes what the Arab region is, is at the heart of the process of Arab (regional) identification, that is the Arab feeling of belonging to an Arab (topographically or ideationally speaking) region" (FERABOLLI, 2015, p. 62). 


\section{Feminismo Árabe-Muçulmano}

No ambiente acadêmico brasileiro, é comum intercambiar no discurso o feminismo árabe e o feminismo muçulmano ao se referir às feministas árabes; não são, entretanto, categorias identitárias necessariamente correspondentes (ABU-LUGHOD, 2001; BAHRAMITASH, 2010; HO, 2010). Entendemos ser mais adequado adotar a nomenclatura "feminismo árabe-muçulmano/islâmico": o feminismo árabe inevitavelmente se depara com obstáculos cultural-religiosos islâmicos (ABU-LUGHOD, 2001), enquanto o feminismo brasileiro, por exemplo, inevitavelmente se depara com obstáculos cultural-religiosos cristãos. Sabemos que um feminismo árabe não necessariamente é islâmico e um feminismo islâmico não necessariamente é árabe (ADLBI SIBAI, 2006); o eixo social "religião” neste caso diz respeito ao exercício religioso individual da ativista feminista (BILGE; HILL COLLINS, 2016). No entanto, o feminismo islâmico é interseccionado por experiências de xenofobia às nações árabes e ofeminismoárabeé interseccionado por experiências de islamofobia, fenômenos difundidos internacionalmente pelo contexto da chamada Guerra ao Terror.

Para maior eficácia, nos referiremos ao feminismo do MundoÁrabe como feminismoárabe-muçulmano, uma vez que os contextos políticos internacionais são centrais para entender ofenômeno nos seus estudos:

Os termos feminismo árabes ou às vezes também, feminismo muçulmano, se utilizam para fazer referência a um suposto feminismo de corte laico e secular similar ao ocidental que se localiza geograficamente nos países árabes e/ou muçulmanos. Ambos os termos, tanto por parte de observadores externos como pelas mesmas feministas que assim se definem, têm sido empregados indistintamente nas equações dicotômicas que enfrentariam dita tipologia com a de um islamismo patriarcal. No entanto, nem os movimentos feministas árabe-muçulmanos são laicos no sentido estrito com que é empregado o termo - já que se reconhecem como muçulmanas, falam também do Islã, o redefinem e fazem tafsir do Corão e do hadiz e iÿtihad, nem os movimentos islamistas conformam um bloco homogêneo, nem muito menos seus discursos e linguagens estão homogeneizados, especificamente, naquilo a que as questões femininas e feministas se referem (ADLBI SIBAI, 2015, p.102 103 , tradução nossa). ${ }^{15}$

A maior dificuldade ao se falar deste feminismo de um lugar do Sul altamente ocidentalizadoé a aparente incompatibilidade entre feminismo, a origem árabe e a religião islâmica, por serem estas últimas duas variáveis que caem em categorias reducionistas dicotômicas de tradição/modernidade e identidade/alteridade. Devemos reconhecer, porém, que o contexto nacional em que escrevemos é, também, marcado por essas dicotomias; vide, por exemplo, a necessidade de mulheres cristãs defenderem a compatibilidade de suas crenças pessoais com o acesso a direitos reprodutivos ${ }^{16}$.

A antropóloga paquistanesa Saba Mahmood afirma a possibilidade de um feminismo que não se desloque das crenças individuais ao explorar diferentes modalidades de agência. Segundo a antropóloga, tal conceito, quando invocado pelas feministas brancas, localiza a agência neces sariamente no desafio diretoà dominação masculina, subordinando-oà ideia tradicional de liberdade: para feministas liberais, "Para que um indivíduo [mulher] seja livre, as ações dela devem ser consequência de sua 'própria vontade' em vez daquela de um costume, tradição ou coerção social” (MAHMOOD, 2005, p. 11, tradução nossa). ${ }^{17}$ No entanto, ao criticar o sistema de crenças e costumes orientais, as feministas ocidentais esquecemse da máxima de que nenhuma mulher é livre sob o sistema patriarcal, portanto as ocidentais também não o são (MAHMOOD, 2005).

\footnotetext{
15 “Los términos feminismo árabe o a veces también, feminismo musulmán, se utilizan para hacer referencia a un supuesto feminismo de corte laico y secular similar al occidental que se ubica geográficamente em los países árabes y/o musulmanes. Ambos términos, tanto por par te de observadores externos como por las mismas feministas que así se definen, han sido empleados indistintamente em las ecuaciones dicotómicas que enfrentarían dicha tipología com la de un islamismo patriarcal. Sin embargo, nni los movimientos feministas arabo-musulmanes son laicos em el sentido estricto com el que es empleado el término - ya que se reconocen como musulmanas, hablan también de Islam, lo redefinen y hacen tafsir del Corán y del hadiz e iÿtihad, ni los movimientos islamistas conforman un bloque homogéneo, ni mucho menos sus discursos y lenguajes están homogeneizados, específicamente, em lo que a las cuestiones femeninas y feministas se refiere” (ADLBI SIBAI, 2015, p. 102-103).

16 Evidenciados pelas organizações feministas Católicas pelo Direito de Decidir e Evangélicas pela Legalização do Ab orto.

17 "In order for an individual to be free, her actions must be the consequence of her 'own will' rather than of custom, tradition, or social coercion" (MAHMOOD, 2005, p. 11).
} 
Em consonância e em complementaridade com o exposto, Abu-Lughod argumenta que os feminismos do Norte desconsideram o passado - e por vezes o presente - das sociedades colonizadas ao apontar a privação de liberdades individuais como o único problema central das mulheres. Apagam, assim, outros sofrimentos, causados pelas ocupações estrangeiras: pobreza, falta de acesso à saúde, à água, desnutrição etc. (ABU -LUGHOD, 2013). Dessa forma, as interseções que constituem as opressões patriarcais vividas pelas mulheres muçulmanas são atenuadas e a política internacional não é responsabilizada pelas opressões de gênero causadas pelos conflitos. A problemática da liberdade individuale das demais opressões (de gênero, classe e religião) é reduzida ao que ela e demais autoras denominam “a questão do véu” (ABULUGHOD, 2013).

Abu-Lughod sugere, então, a aceitação da diferença, não como resignação, mas como problematização da crença ocidental de que as mulheres árabes só serãolivres quando forem “comonós”. Istoé, sugere que as mulheres árabes só serão livres quando seus países forem livres da intervenção externa, uma vez que liberdade para elas pode ser muito distinta da liberdade ocidental: "Emancipação, igualdade e direitos são parte de uma linguagem universal ou apenas um dialeto particular? (...) Outros desejos poderiam ser tão desejáveis quanto para as pessoas? (...) Viver sem guerra?” (ABU LUGHOD, 2013, p. 45 , traduçãonossa). ${ }^{18}$

Para conectar a crítica do feminismo ocidental à formulação dos preceitos de um feminismo árabe-muçulmano, Nawar Golley aponta que as necessidades de mudanças para mulheres árabes não sãonem maiores nem menores do que para mulheres em outras localidades (GOLLEY, 2004): a descrição feminista orientalista de que a vida no Oriente Médioé excessivamente diferente criou o mito de que a agência das mulheres árabes não seria compatível com qualquer feminismo.

Apesar da crítica local de que o feminismo é uma nova colonização, dada a origem ocidental e liberal do movimento (GOLLEY, 2004), o feminismo das mulheres árabes tampouco é reconhecido e validado no Ocidente. Por isso, Golley contrapõe tanto as visões orientalistas quanto as visões anti-colonialistas das representações das mulheres árabes, que seria uma subrrepresentação da subrrepresentação da cultura árabe. Ela aponta que as práticas sociais atreladas à religião não são independentes dos contextos socioeconômicos e políticos e que, enquanto atividade humana, estão sujeitas a mudanças. Consequentemente, é preciso entender como o Islã é manipulado por grupos sociais visando interesses políticos e econômicos e como é feita sua adaptação aos contextos institucionais. Defende, como as demais autoras, que "Algumas práticas religiosas podem ser fatores determinantes na opressão de mulheres; mas elas não são as únicas” (GOLLEY, 2004, p. 522, tradução nossa) ${ }^{19}$, atestando que não é incoerente o exercício da religião por uma feminista, visto que se criticam os aspectos opressivos que permeiam as relações entrefiéis.

Mervat Hatem rechaça o pressuposto ocidental de que o feminismo não é compatível com as sociedades do Mundo Árabe. Isto advém da sua definição do feminismo como um conjunto de ferramentas analíticas e críticas que, ao informarem estratégias de ação, treinam a consciência das mulheres para compreender suas relações consigo mesmas, com grupos nacionais, regionais e internacionais (HATEM, 2013).

O feminismo, em qualquer sociedade, é refletido nas conquistas das mulheres na educação, no serviço público e nos direitos políticos, explicitando as desigualdades entre classes e nacionalidades, chamando atenção para a necessidade de construir pontes e/ou formar alianças internacionais. Estes preceitos, identificados por nós como comuns e condutores aos argumentos das autoras, são perpassados, no entanto, por uma perspectiva originalmenteliberal e pouco sensível aos eixos de análise interseccional imprescindíveis ao feminismo. O paradoxo dos feminismos pós -coloniais - e do árabe-muçulmano especificamente - é visível pela mobilização de direitos e conquistas oriundos do escopo liberal e, portanto, do Ocidente. Com isso, reflete-se a questão da própria autonomia de optar pela defesa por esses direitos livre de influência colonialista (HATEM, 2013).

18 "Are emancipation, equality and rights part of a universal language or just a particular dialect? (...) Might other desires be as meaningful for people? 
Dada a importância do contexto nacional para a articulação de uma rede feminista transnacional, Hatem considera imprescindível para o feminismo árabe a crítica dos projetos modernistas dos Estados árabes, por terem existido em contextos coloniais que reproduziram e consolidaram a manutenção das mulheres nas funções domésticas e de maternidade (HATEM, 2013) como seus serviços prestados à nação (AL -ALI, 2005; AL-ALI e PRATT, 2006, 2008, 2009; MAHMOOD, 2005). A leitura historiográfica de Hatem sobre a modernização dos Es tados árabes indica oimportante papel das instituições na promoção da igualdade de gênero para mulheres das classes média e alta (HATEM, 2013). Contudo, a diferença de acesso às oportunidades por mulheres de classes sociais diferentes inibiu avanços nos direitos das trabalhadoras e na formação de alianças políticas. Segundo a autora, as mulheres incorporadas à burocracia do Estado acabavam por transferir sua lealdade do próprio gênero para o Estado: "O resultado dessa barganha silenciosa enfraqueceu o poder das mulheres de negociar com o Estado" (HATEM, 2013, p. 97, tradução nossa). ${ }^{20}$

A aliança feminina com os governos árabes modernos foi um fator extremamente relevante para o feminismo árabe, de acordo com a autora. O Estado controlava a agenda de gênero ao fazer concessões igualitárias que satisfizessem os interesses de classe média e alta e assumia o papel paradoxal de promover direitos formais ao mesmo tempo em que dividia a população feminina (HATEM, 2013). Do ponto de vista estatal, porém, o papel de inclusão das mulheres no sistema educacional e no funcionalismo público é tanto mais funcional que paradoxal, pois expressa um projeto político patriarcal de promover concessões que sirvam à manutenção do status quo nacional em momentos de crise econômica. Ademais, o eixo classista é perceptível, pois esses direitos formais tinham como favorecidas apenas as mulheres de classe média a alta. Ou seja, de qualquer forma, o Estado não promovia mudanças estruturais visando a igualdade de gênero e a igualdade social entre as próprias mulheres.

Este histórico faz com que haja um desejo de confiança no Estado enquanto motor da mudança social e, no entanto, o séculoXX trouxe as intervenções militares no Oriente Médio como uma mudança no eixo de confiabilidade do Estadoárabe para atores e organismos internacionais:

Alianças com grupos de mulheres ativos nas arenas internacionais oferecem resultados contraditórios: constrangem esses Estados, mas, ao mesmo tempo, podem ser usados para reproduzir o velho argumento de que as mulheres e/ou grupos feministas não são cidadãos leais e que encorajam intervenções estrangeiras nos assuntos da nação (HATEM, 2013, p. 98). ${ }^{21}$

Este trecho explicita a preocupação e desconfiança latentes ao feminismo árabe-muçulmano: o desejo das ativistas de se articularem internacionalmente com feministas de outras regiões do globo, mas com o receio de que a articulação com sociedades mais ocidentalizadas (a depender do histórico de colonização e desenvolvimento nacional) configure um sutil intervencionismo internacional. Essa preocupação se estende a organizações tais quais UNICEFe ONU Mulheres, cuja ajuda financeira e de operacionalização de projetos de assistência social às populaçõesfemininas ainda gera desconfiança pelo teor liberal da promoção de independência feminina através da inserção no mercado de trabalho. Hatem (2013) afirma ainda a possibilidade de apoiar o projeto feminista islâmico sem ser favorável ao projeto político de criação de um Estadoreligioso islâmico.

Nesse sentido, Omaima Abou-Bakr afirma que o feminismo muçulmano tem origem em um movimento teológico de revisionismo do machismo na prática religiosa. Tem por objetivo criticar a teologia do patriarcado e contestar as justificativas supostamente religiosas da hierarquia de gênero, na busca pela igualdade e a justiça de gênero na cultura islâmica como um todo, elementos que não fazem parte do projeto político islâmico (ABOU-BAKR, 2015). De acordo com Abou-Bakr, as feministas muçulmanas são independentes e manifestam posições intelectuais e políticas distintas das dos

20 "The result of this silent bargain has weakened the power of women to negotiate with the state" (HATEM, 2013, p. 97).

21 "Alliances with active women's groups in the international arenas offer a mixed outcome: they embarass these states, but at the same time they can be used to reproduce the old argument that women and/or feminist groups are not loyal citizens, and that they encourage foreign intervention in the affairs of the nation1" (HATEM, 2013, p. 98). 
demais ativistas muçulmanos. Ao observar a atuação das feministas muçulmanas egípcias, que se opõem ao governo da Irmandade Muçulmana, ela vê a necessidade de definir preceitos éticos para o seu envolvimento político (ABOU-BAKR, 2015). Se, de acordo com a autora, o objetivo primordial do feminismo é o combate ao autoritarismo patriarcal e à desigualdade de gênero, é fundamental se opor a regimes autoritários e injustos; se uma feminista se forma ao expor e rejeitar quaisquer práticas excludentes, ela não pode ser complacente e ignorar padrões de monopólio da violência pelo Estado. Não menos importante, qualquer feminismo deve considerar as especificidades de classe e as particularidades das mulheres pobres e marginalizadas (ABOU-BAKR, 2015).

Dados estes fatores, que são a base de qualquer feminismo, Abou-Bakr sustenta que feministas muçulmanas não se alinham ao projeto político islâmico que, como a maioria dos projetos políticos religiosos no mundo, é essencialmente patriarcal.Em linhas gerais, ofeminismo muçulmano:

(...) é capaz de sublinhar a convergência do patriarcado autoritário tanto religiosa quanto politicamente através da conceituação, invocando preceitos específicos e eticamente relevantes: resistir a todas as formas de zulm (injustiça), istikbar (orgulho) e baghdy/tughian (transgressão) na busca de uma 'adl (justiça) holística (ABOU-BAKR, 2015, p. 200, tradução nossa). ${ }^{22}$

Assim como as demais autoras, Adlbi Sibai acredita que a questão das mulheres árabes acaba presa na bipolaridade entre a retórica da modernização e emancipação das sociedades árabes (segundo moldes ocidentais) e a retórica da submissão ao Islã e à tradição (ADLBI SIBAI, 2016), novamente legitimando nossa crítica quanto ao emprego de valores liberais e entendidos como ocidentais. Ambos os polos - de simultânea modernização e submissão à tradição se retroalimentam e sãoigualmente machistas pois, como ela diz, a agência não pertence à mulher árabe em nenhum dos cenários. Sua proposta, então, é uma terceira via em que discurso e ação das feministas árabes -muçulmanas sejam analisados a partir do lugar da enunciação (ADLBI SIBAI, 2016). Sibai, aqui, demonstra estar tanto mais próxima ao entendimento do feminismo árabe-muçulmano do que as demais autoras. Seu sucesso pode ser atribuído à sua experiência pessoal de ascendência síria, prática do islamismo com adesão ao uso do hijab, crítica ao capitalismo e ao intervencionismo internacional. Todos estes resumidos pela sua presença no eixo etnia-religião-nacionalidade, experienciado na Espanha, onde foi criada e exerce suas atividades acadêmicas.

Novamente, ela denuncia a generalização do feminismo árabe-muçulmano pelas feministas liberais e pela mídia ocidental na figura da "mulher muçulmana com hijab", que apontam uma suposta incompatibilidade entre ofeminismo e o Islã (ADLBI SIBAI, 2016). Enquanto, ela mesma, mulher muçulmana de origem árabe que veste o hijab, considera que esta dificuldade de exposição foi imposta pelo Ocidente ao feminismo árabe -muçulmano principalmente após o 11 de Setembro, que teria exoticizado a realidade árabe na figura descrita acima. Desenvolvendo seu argumento, a autora considera:

A epígrafe mulhermuçulmana com hijab simboliza um sujeito passivo de estudo, convertido em objeto de análise e intervenção de características bem definidas: monolítico, atemporal, analfabeto e sexualmente reprimido, é o símbolo da opressão feminina universal, vítima não salvável do sistema patriarcal; não fala, está incapacitado para a agência social e é definitivamente 'inferior'. Ademais, sempre veste um véu ou hijab como símbolo de sua 'sujeição' (...) É através da mulher muçulmana com hijab que se apresentarão e representarão todas as realidades árabes e muçulmanas (ADLBI SIBAI, 2016, p. 114, tradução nossa). ${ }^{23}$

Além da importância do discurso simbólico, a autora lembra que as feministas ocidentais ocultam a responsabilidade direta do Ocidente na perpetuação de "situações de crises, guerras e fome que prejudicarão o

22 "(...) is able to underline the convergence of both theological and political authoritarian patriarchy through conceptualizing and invoking specific, relevant ethical tenets: resisting all forms of zulm (injustice), istikbar (pride), and baghdy/tughian (transgression) for the pursuit of a holistic 'adl (justice)" (ABOU-BAKR, 2015, p. 200).

23 "El epígrafe mujer musulmana com hiyab simboliza un sujeto pasivo de estudio, convertido en objeto de análisis e intervención de características bien definidas: monolítico, atemporal, analfabeto y sexualmente reprimido es el símbolo del opresión feminina universal, víctima insalvable del sistema patriarcal; no habla, está incapacitado para la agencia social y s em definitiva "inferior". Además, siempre porta un velo o hiyab como símbolo de su "sujeción” (...) Es a través de la mujer musulmana com hiyab que se presentarán y representarán todas las realidades árabes y musulmanas” (ADLBI SIBAI, 2016, p. 114). 
desenvolvimento dos direitos e liberdades de todos os indivíduos da sociedade (as mulheres e as crianças em primeiro lugar)” (ADLBI SIBAI, 2016, p.116, traduçãonossa). ${ }^{24}$

\section{Conclusão}

Diante dos elementos do feminismo pós-colonial a partir dos quais ofeminismo árabe-muçulmano se desenvolve, podemos apontar para a notável contribuição teórica-epistemológica deste aos debates feministas em RI. Apesar das diferenças geográficas e da variável origem/nacionalidade explícita pela nomenclatura “árabe”, as abordagens disponíveis se aproximam pelo reconhecimento mútuo da condição de colonizadas e de combate à subalternidade dentro de suas próprias sociedades. Por tal motivo, é tão viável quanto necessário o conhecimento da pesquisadora brasileira sobre esses feminismos "distantes" de modo a diversificar as possibilidades teóricas com as quais trabalhar nas RI.

Ademais, os feminismos do Sul reconhecem que os marcadores da colonização permanecem na institucionalidade, na socialização feminina e na atuação econômica das mulheres de sociedades administradas ou ocupadas por países do Norte. Considerando-se, ainda, que a mulher árabe se constitui além da raça e da subalternidade de seu próprio sistema social, sendo afetada direta, individual e coletivamente, pela política internacional protagonizada pelo Norte. Outrossim, a teoria feminista das RI não trata dos eixos da religião, nacionalidade e territorialidade, de extrema relevância para as sociedades árabes, destacando majoritariamente os aspectos securitários.

Embora haja especificidades regionais, ser feminista no Sul Global é indissociável da luta contra a violência neoimperialista, contra os fundamentalismos religiosos, contra as desigualdades sociais, em favor da representatividade e da participação política, em favor do acesso à educação formal, contra a exploração sexual. Pode-se dizer, portanto, que uma interseção entre os feminismos do Sul - portanto, fator que se deve preponderante nos temas de aproximação entre o feminismo árabe-muçulmano, os pós-coloniais e os decoloniais - é fundamental à resolução de impasses na luta por direitos que compartilham origem e valores com os movimentos imperialistas. Pois, os direitos e conquistas reivindicados pelas mulheres do Terceiro Mundo o são justamente de modo a alijar-se de interferências externas oriundas do Norte. E, no entanto, este paradoxo ainda não foi resolvido, o que pode dificultar a difusão dos valores feministas nas sociedades do Sul, muitas das quais recusam quaisquer elementos que as lembrem dos tempos coloniais. Isso só será possível, nas pesquisas em RI, se expandirmos o escopo teórico com os quais trabalhamos, sem desprezar as teorias do Norte, mas problematizá-las em relação às propostas feministas do Sul.

É importante, assim, que as vertentes feministas dialoguem de modo a compor um movimento feminista mundial, em que a luta das mulheres de um continente seja reconhecida e relevante para as mulheres de outro continente. Em vista disso, a pergunta de pesquisa é respondida de modo a confirmar a hipótese de que as feministas árabes e muçulmanas contribuem para o avanço do debate teórico feminista do Sul Global nas RI, à medida em que seus trabalhos representam mais um elo para ligar os feminismos doSul. Ao adicionar os eixos religião, nacionalidade e etnia às análises interseccionais, o feminismo árabe-muçulmano evidencia como os reflexos da colonização incidem sobre marcadores identitários das mulheres em sua diversidade. Sob essa perspectiva, através dessas lentes feministas, é possível revelar como e quais as estruturas sociais que perpetuam a marginalidade das mulheres na política, na economia, na religião, na cultura e como suas potencialidades são contingenciadas. É nesse sentido que consideramos ser profícua a incorporação de contribuições feministas diversas à teoria feminista das Relações Internacionais, justamente por representarem perspectivasnão-estadocêntricas das consequências dos rumos da política internacional.

24 "situaciones de crisis, guerras y hambrunas que prejudicarán el desarrollo de los derechos y libertades de todos los indivíduos de la sociedad (las mujeres y los niños en primer grado)” (ADLBI SIBAI, 2016, p.116). 


\section{Referências}

ABOU-BAKR, Omaima. Islamic Feminism and the Equivocation of Political Engagement. IN: EL SAID, Maha; MEARI, Lena; PRATT, Nicola. Rethinking Gender in Revolutions and Resistance. Lessons from the Arab World. Zed Books, Londres, 2015.

ABU-LUGHOD, Lila. “Orientalism” and Middle East Feminist Studies. Feminist Studies, V. 27, N. 1, p. $101-113,2001$. Do Muslim Women Need Saving? Harvard University Press, Cambridge, Massachussetts e Londres, 2013.

ACKERLY, Brooke. Feminist Methodological Reflection. In: KLOTZ, Audie; PRAKASH, Deepa (Ed.). Qualitative Methods in International Relations. Palgrave Macmillan, 2008.

ACKERLY, Brooke; TRUE, Jacqui. Studying the struggles and wishes of the age: feminist theoretical methodology and feminist theoretical methods. In: ACKERLY, Brooke; STERN, Maria; TRUE, Jacqui. Feminist Methodologies for International Relations. Cambridge University Press, 2006.

ADLBI SIBAI, Sirin. La cárcel del feminismo: Hacia un pensamiento islámico decolonial. Ediciones Akal, México, 2016.

AL-ALI, Nadje. Reconstructing Gender: Iraqi Women between Dictatorship, War, Sanctions and Occupation. Third World Quarterly, Reconstructing Post-Saddam Iraq: A Quixotic Beginning to the 'Global Democratic Revolution'. Taylor \& Francis, v. 26, n. 4/5, p. 739-758, 2005.

AL-ALI, Nadje; PRATT, Nicola. Women in Iraq: Beyond the Rhetoric. Middle East Report, Dispatches from the War Zones: Iraq and Afghanistan. Middle East Research and Information Project, n. 23, p. 18-23, 2006

Women's Organizing and the Conflict in Iraq since 2003. Feminist Review, War. Palgrave Macmillan Journals, n. 88, p. 74-85, 2008.

Women and War in the Middle East. Transnational Perspectives. Zed Books, edição digital, 2009.

BAHRAMITASH, Roksana. The War on Terror, Feminist Orientalism and Orientalist Feminism: Case Studies of Two North American Bestsellers. Critique: Critical Middle Eastern Studies, v. 14, n. 2, p. 221-235, 2010.

BILGE, Sirma. Beyond Subordination vs. Resistance: An Intersectional Approach to the Agency of Veiled Muslim Women. Journal of Intercultural Studies, v. 31 n. 1, pp. 9-28, 2010.

BILGE, Sirma; HILL COLLINS, Patricia. Intersectionality. Polity Press, 2016.

DALEY, Patricia; FIDDIAN - QASMIYEH, Elena. Routledge Handbook of South-South Relations. Routledge, 2020.

FERABOLLi, Silvia. Arab Regionalism. A Post-Structural Perspective. Routledge, 2015.

GOLLEY, Nawar Al-Hassan. Is feminism relevant to Arab women? Third World Quarterly, v. 25 n. 3, pp. 521-536, 2004.

HATEM, Mervat. What do women want? A critical mapping of future directions for Arab Feminists. Contemporary Arab Affairs, v.6 n.1, pp. 91-101,2013.

HO, Christina. Responding to Orientalist Feminism. Women's Rights and the War on Terror. Australian Feminist Studies, v. 25 n. 66 , pp. 433-439, 2010 .

MAHMOOD, Saba. Politics of Piety: The Islamic Revival and the Feminist Subject. Princeton University Press, 2005.

MOHANTY, Chandra Talpade. Under Western Eyes: Feminist Scholarship and Colonial Discourses. boundary 2, v. 12 n. 3, pp. 333-358, 1984.

MOHANTY, Chandra Talpade; RUSSO, Ann; TORRES, Lourdes (org.). Third World Women and the Politics of Feminism. Indiana University Press, 1991.

SPIVAK, Gayatri Chakravorty. Pode o Subalterno Falar? Editora UFMG, Belo Horizonte, 2010.

SYLVESTER, Christine. Feminist International Relations. An Unfinished Journey. Cambridge University Press, edição digital, 2004.

SYLVESTER, Christine. The Art of War/The War Question in (Feminist) IR. Millennium: Journal of International Studies, v. 33, n. 3, p. 855-878, 2005.

TICKNER, J.Ann. A Feminist Voyage Through International Relations. Nova York: Oxford University Press, $1^{\text {a }}$ ed., 2014.

TICKNER, J. Ann. You Just Don't Understand: Troubled Engagements between Feminists and IR Theorists. In: International Studies Quarterly, n. 41, 611-632,1997.

YUVAL-DAVIS, Nira. Intersectionality and Feminist Politics. European Journal of Women’s Studies, v. 13 n. 3, pp. 193-209, 2006. 
Funções de colaboração exercidas

Sophia Teixeira e Souza:

Conceituação; Metodologia; Análise formal; Escrita (primeira redação);

Julia Bertino Moreira:

Conceituação; Metodologia; Supervisão; Escrita (revisão e edição);

Informações fornecidas pelos(as) autores(as) de acordo com a Taxonomia de Funçóes de Colaborador (CRediT) 